\title{
Tuning the performance of pyrido[4,3-b]pyrazine-EDOT hybrid polymers for use as neutral green electrochromic materials
}

\author{
Faqi $\mathrm{Hu}^{1,2}$, Qi Zhao ${ }^{1,2}$, Ying $\mathrm{Li}^{3, *}$, Ximei $\mathrm{Liu}^{1, *}$ \\ ${ }^{1}$ School of Pharmacy, Jiangxi Science and Technology Normal University, Nanchang 330013, \\ Jiangxi, PR China \\ ${ }^{2}$ Flexible Electronics Innovation Institute (FEII), Jiangxi Science and Technology Normal University, \\ Nanchang 330013, Jiangxi, PR China \\ ${ }^{3}$ Business School, Jiangxi Science and Technology Normal University, Nanchang 330013, Jiangxi, PR \\ China \\ *E-mail: 916749930@qq.com ; 1xm5812@163.com
}

doi: $10.20964 / 2021.02 .59$

Received: 8 November 2020 / Accepted: 18 December 2020 / Published: 31 December 2020

Conjugated electrochromic polymers have been reported for many years, owing to their multicolor display, minimal energy consumption, and excellent stability. Among them, there are very few polymers with a neutral green color and desirable performance. In this work, we developed a series of neutral green/gray electrochromic materials by tuning the performance of pyrido[4,3-b]pyrazine-EDOT hybrid polymers. The synthesized precursors/polymers were characterized by optoelectronic, morphological, computational, electrochemical, and electrochromic methods. Results showed that introducing a methylsubstituted pyrido[4,3-b]pyrazine acceptor into the molecular design improved the solubility of the precursors (EPMPE and BEPMPBE) and the redox stability of the corresponding polymers (PEPMPE and PBEPMPBE). On the other hand, the extended conjugated chain redshifted the absorption spectra of the polymers (PBEPPBE and PBEPMPBE), which changed their color from neutral green to gray, but also reduced their optical bandgap, and further improved their optical contrast, response time, and even coloration efficiency in the near-infrared region. The excellent electrochromic performance and rare color of the pyrido[4,3-b]pyrazine-EDOT hybrid polymers make them promising materials for use in near-infrared electrochromic applications.

Keywords: Conjugated polymer, Electrochromism, Pyrido[4,3-b]pyrazine, EDOT, Green color

\section{FULL TEXT}

(C) 2021 The Authors. Published by ESG (www.electrochemsci.org). This article is an open access article distributed under the terms and conditions of the Creative Commons Attribution license (http://creativecommons.org/licenses/by/4.0/). 